\title{
Transpupillary Thermotherapy for Classic Subfoveal Choroidal Neovascularization: A case report
}

\author{
AO Hassan FRCS, FRCOphth, FWACS; O Oderinlo FRCS, DRCOphth; O Okonkwo, FRCS, \\ DRCOphth; FO Oluyadi FWACS, FMCOphth; AO Ogunro, FWACS, FMCOphth; SA Oke, DO \\ WACS, MSc
}

Eye Foundation Hospital, 27 Isaac John Street, Ikeja GRA, Lagos

\section{SUMMARY}

Aim: To report a case of successful treatment of a classic subfoveal choroidal neovascularization with a transpupillary thermotherapy protocol.

Case Report: A 67-year old pensioner presented with a sixmonth history of reduced vision in both eyes. He had been previously diagnosed with primary open angle glaucoma.

After anterior and posterior segment examination and fundus fluorescein angiography were done, a diagnosis of a classic subfoveal choroidal neovascularization secondary to exudative age-related macular degeneration OS with bilateral cataracts and primary open angle glaucoma OU was made.

Complete resolution of the choroidal neovascular membrane was achieved with transpupillary thermotherapy.

Key words: transpupillary thermotherapy, age-related macular degeneration, subfoveal choroidal neovasularization, fundus fluorescein angiography

\section{INTRODUCTION}

Transpupillary thermotherapy (TTT) is a low irradiance, large spot size, prolonged exposure (long pulse), infrared laser photocoagulation protocol $^{1}$ which is presently being investigated for use in the treatment of choroidal neovascular membranes.

Its main advantages are that the infrared lasers are absorbed less by xanthophyll pigments and thus damage to the nerve fibre layer is minimized. Compared to the argon laser, the infrared diode is also poorly absorbed by haemoglobin, allowing an improved ability to treat through preretinal and subretinal haemorrhage. ${ }^{2}$

The relatively larger spot size of the laser beam also enables treatment of larger lesions with a single burn. TTT has only been recently put to use at The Eye Foundation, Ikeja, Lagos. The case being reported here is one of a patient diagnosed with a classic subfoveal choroidal neovascularization that was treated with TTT.

\section{CASE REPORT}

$\mathrm{Mr} \mathrm{J} \mathrm{AO}$, a 67-year-old pensioner, presented to our hospital on the $9^{\text {th }}$ of December 2004 with a complaint of reduced vision in both eyes, over a period of 6 months. He wears glasses and had earlier been diagnosed with chronic primary open angle glaucoma. He had been on treatment for systemic hypertension for eight years and had had bilateral trabeculectomies in May 2002.

Examination on presentation revealed visual acuities of hand movements OD and counting fingers at 2 metres OS. Pupillary light reactions and extraocular muscle movements were normal in both eyes. Both conjunctivae showed cystic filtering blebs with intraocular pressures of $12 \mathrm{mmHg}$ OD and $16 \mathrm{mmHg}$ OS by applanation tonometry. Gonioscopy revealed open angles of Shaffer grade 3-4 in both eyes. There were definite posterior subcapsular cataracts in both eyes but worse in the right.

A fundus examination revealed bilateral intermediate and large macular drusen, with macular subretinal haemorrhages OS and cup to disc ratio of 0.8 in both eyes.

The patient was assessed to have:

1. Bilateral age-related macular degeneration, exudative OS

2. Bilateral posterior subcapsular cataracts worse OD

3. Bilateral primary open angle glaucoma

He underwent a fundus flourescein angiography on the $16^{\text {th }}$ of December 2004 which revealed a classic subfoveal choroidal neovascularization in the left eye (figures $1 \mathrm{a}$ and $1 \mathrm{~b}$ ) the right eye had no choroidal neovascular lesion.

Subsequently, he had TTT laser treatment of his left eye on the same day the angiography was done. Parameters used were spot size $3.00 \mathrm{~mm}$, power setting $500 \mathrm{~mW}$ and duration $60 \mathrm{~s}$. He also had a right extracapsular cataract extraction with a posterior chamber implant on the $25^{\text {th }}$ of January, 2005.

${ }^{*}$ Correspondence: O Oderinlo, Eye Foundation Hospital 27 Isaac John Street, Ikeja, Lagos. 


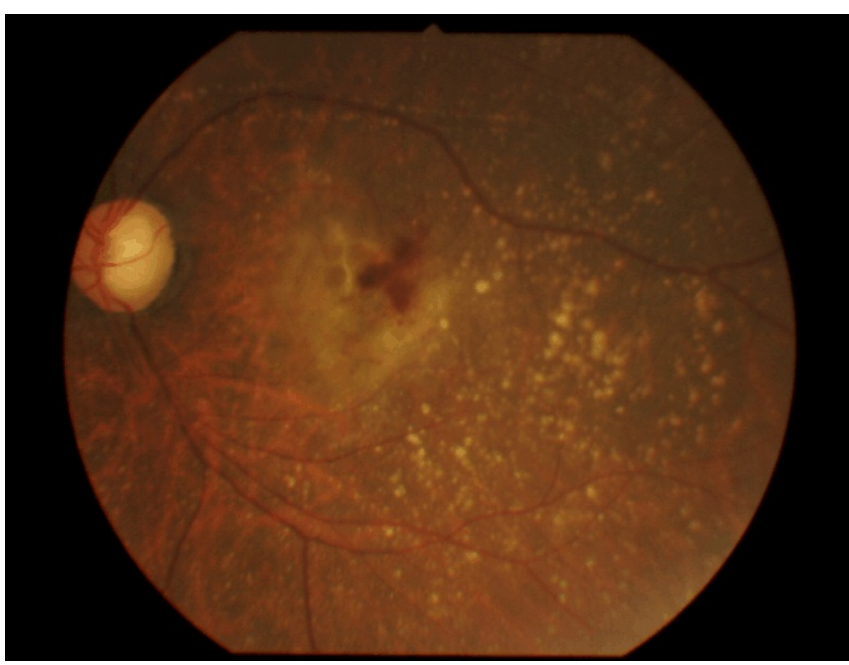

Figure 1a

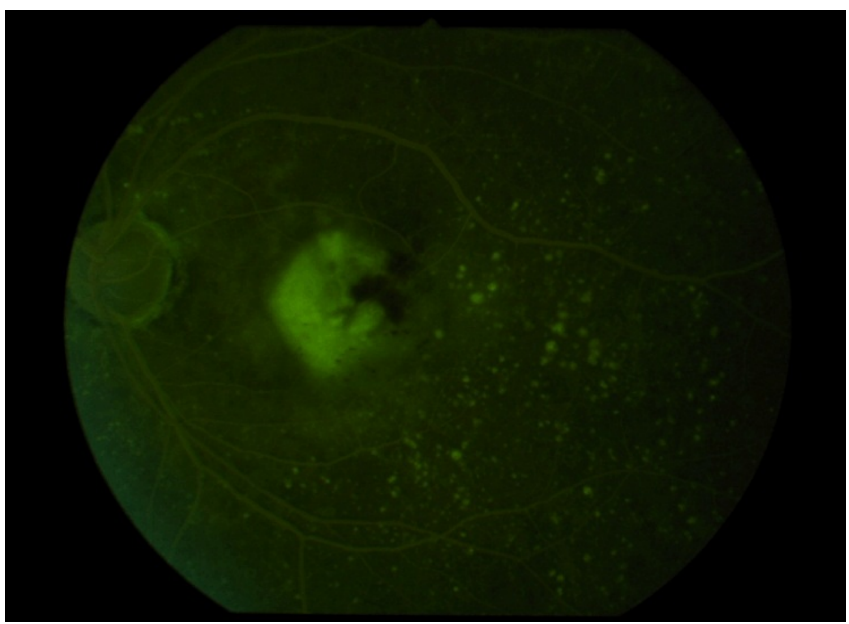

Figure 1b

During his clinic visit on the $25^{\text {th }}$ of May 2005, visual acuities were counting fingers OD and 6/60 OS. These improved with refraction thus:

OD- $0.50 \mathrm{DS} /-4.00 \mathrm{dcyl}^{*} 10=6 / 36$

OS+ $0.50 \mathrm{DS} /-1.50 \mathrm{dcyl} \mathbf{H}^{*} 80=6 / 36$

Add $+3.00 \mathrm{OS}=\mathrm{N} 36$

Anterior segment findings were normal with the exception of the right pseudophakia and posterior subcapsular cataracts in the left eye. Both discs were pale and cupped with cup to disc ratio of 0.8 and normal intraocular pressures.

Figure 2 shows a complete resolution of the subfoveal lesion at 2 months after treatment, with his glaucoma control. At last visit he was taking G Betoptic $0.5 \% 12$ hourly OU and one antioxidant tablet twice daily. He felt much better and could even read large print. He was able to navigate without assistance.

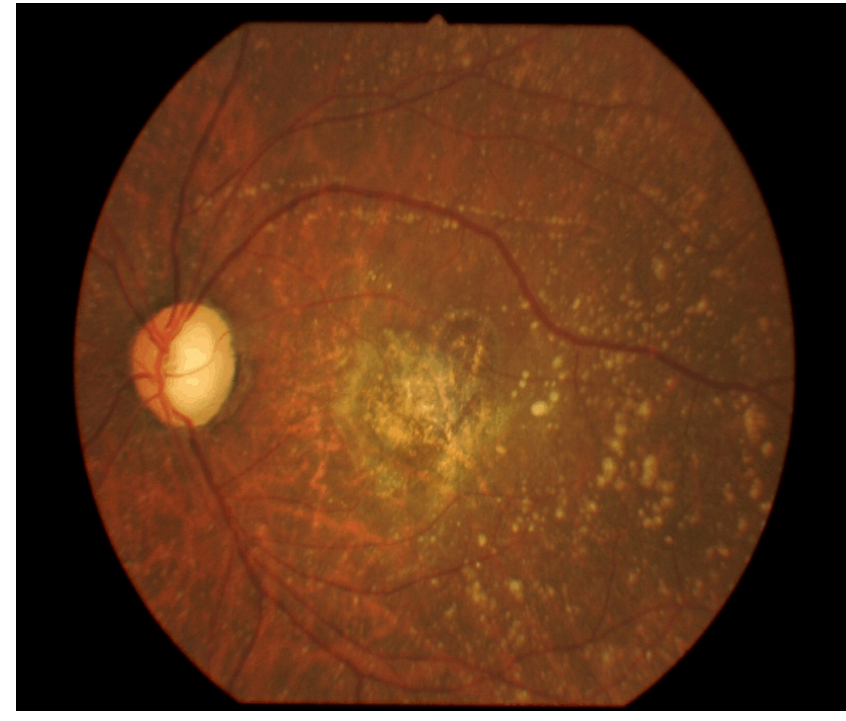

Figure 2

\section{DISCUSSION}

Subfoveal choroidal neovascularization still remains a management challenge to ophthalmologists. Medicare guidelines in the United States of America presently favour photodynamic therapy (PDT) for predominately classic subfoveal neovascularization. ${ }^{3}$ However, in our environment, this treatment modality is very expensive; each vial of visodyne costs E850.00, which is approximately $\$ 212,500.00$. This excludes the cost of fundus fluorescein angiography and the surgeon's fees. It should also be noted that repeated treatment sessions are often needed for PDT and that not all subfoveal neovascular lesions respond well to this treatment modality.

The advent of multiple research into the use of TTT in the management of these lesions is, therefore, of great interest. TTT has been evaluated for use in both occult and classic choroidal neovascularization and encouraging results have been reported., ${ }^{4,6}$

In our hospital TTT is done with the IRIS medical; oculight SLX infrared (810nm) solid state laser with tri-mode, using a slit lamp delivery method and a Goldman's 3 mirror lens. Our preferred parameters of 60 seconds duration, $3 \mathrm{~mm}$ spot size and power settings are usually varied depending on the location and size of the lesion and the patients pain threshold.

TTT in our patient achieved a complete resolution of the choroidal neovascular membrane without adversely affecting his intraocular pressures.

This case report adds a positive word for the ongoing clinical trials on the uses of TTT for choroidal neovascular membranes. 


\section{REFERENCES}

1. Mainster MA, Reichel E. Transpupillary thermotherapy for age related macular degeneration. Long pulse photocoagulation, apoptosis and heat shock proteins. Ophthalmic Surgery Lasers 2000; 359-373.

2. Thach AB, Slipperlay JO, Dugad PU, Sneed SR, Park DW, Cornelius J. Large spot size traspupillary thermotherapy for treatment of occult choroidal neovascularization associated with age related macular degeneration. Arch Ophthalmology 2003; 121: 817-820.

3. Stephan Michel's, Phillip J Rosenfeld. Clinical approach to age related macular degeneration. Review of Ophthalmology 2004; 3(3): 3-7.
4. Algvere PV, Libert C, Lingard G, Seregard S. Transpupullary thermotherapy for predominantly occult choroidal neovascularization in age related macular degeneration with 12 months follow-up. Acta Ophthalmological Scandinavica 2003; 81: 110-117.

5. Allen B Thach, Jack O Sippery, Pravin U Dugal, Scot R Sneed.Large spot size Transpupillary thermotherapy for treatment of occult choroidal neovascularization associated with Age Related Macular Degeneration. Arch ophthalmal 2003; 121: 817-820.

6. Singer MA, Willerson Jr D. Transpupillary thermotherapy choroidal neovascularization presentation. The vitreous society $18^{\text {th }}$ annual meeting, Cancun Mexico January 7-11, 2001. 